\title{
Modelling and numerical simulation of the heat transfer and natural ventilation in storage halls
}

\author{
Nina Penkova ${ }^{1, *}$, Kalin Krumov ${ }^{1}$, Boian Mladenov ${ }^{1}$, and Yordan Stoyanov \\ ${ }^{1}$ University of Chemical Technology and Metallurgy, Department of Silicate Technology, Blvd. Sv. \\ Kliment Ohridski 8, 1756 Sofia, Bulgaria
}

\begin{abstract}
An algorithm for modelling of the heat transfer in storage halls at different combinations of open doors and smoke vents is developed. The models allow numerical simulations of velocity, pressure and temperature fields in the halls in cases of transient and steady state conditions, taking into account the indoor buoyancy, heat sources, heat transfer through the building envelopes and outdoor wind pressures. The models are solved numerically via finite volume method in order to estimate the necessity of additional heating at a design stage of a courier logistic storage hall, situated in the temperate climate zone, at the hardest winter conditions of the region. Recommendations about the organization of the heating and the cargo input are done based on the analyses of the fluid flow and thermal fields at the modelled scenarios.
\end{abstract}

\section{Introduction}

The computational fluid dynamics (CFD) is increasingly used at design activities in the recent decades. It allows obtaining of detail information about the velocity, pressure and temperature fields at heating, ventilation and air conditioning of residential and industrial buildings [1-5]. Different tasks can be solved based on CFD analyses as prediction of pollutions and smoke distribution, determination of proper locations of supply and return vents, heat sources and measuring sensors $[6,7]$.

According to the Bulgarian regulations [8], the conceptual, technical and work projects may include models and computer animation to illustrate the operation of the systems objects of design. Such models are especially useful for accurately defining of parameters that are computed according to the design regulations in a wider range and are not applicable for particular cases. For example, there are established methods for computation of the air exchange rate due to infiltration and natural ventilation in residential, commercial, office buildings and institutions [9, 10]. However, they give approximate solutions for the air exchange, caused by stack and wind effects at tall industrial or storage halls with relatively high intensity of opening of doors at different facades [11]. CFD analyses can be used here to obtain detailed information of the airflows at the natural ventilation, taking into account the specificity of the buildings and the local climate conditions [12, 13].

\footnotetext{
* Corresponding author: nina@uctm.edu
} 
The aim of the present study is to develop and test a model for quick numerical simulation of the heat transfer and natural ventilation in storage logistic halls, allowing estimation of the temperature and fluid flow fields at different combinations of openings and outdoor conditions.

\section{Conception for CFD analysis of the heat transfer at natural ventilation in halls}

A three-dimensional geometrical model of the internal air space of the hall is generated. All doors, windows and smoke vents have to be presented in the model by merged surfaces on the space walls. Different scenario can be simulated accepting them as open (openings) or closed (walls). The air domain is discretized by a mesh of finite volumes in order to solve numerically the system of partial differential equations:

- continuity equation;

- $\quad$ momentum equations at non zero gravity to model the buoyancy;

- energy equation;

- $\quad$ turbulence model;

The air is accepted as an ideal gas: its density is computed by the corresponding equation.

The ventilation channels (if there any) or heating units can be modeled geometrically and subtracted by the volume of the hall space. Ways for modeling the thermal energy supply are presented in Table 1.The surfaces of the inlets and outlets of the correspondent air flows have to exist merged in the geometrical models. Respective boundary conditions for modeling of the air supply and return are applied on them in cases of convective heating installations. At radiant heating, often used in the halls, radiating surfaces also exist in the geometrical models. The radiation heat exchange between the solid surfaces, viewing each other through the transparent air space is modeled in these cases (so called surface-to-surface radiation). These boundaries exchange thermal energy with the air by convection: the processes are obtained as results of the numerical solution without needs of additional boundary conditions.

A simple way to model the heating is the use of heat source in a subdomain, covering the heating unit place: it gives exact solution for the energy input in the space, but an approximate information about its distribution.

The heat source also can be used to model the heat transfer with the cargo, entering in the halls, if it is with temperature, different from the temperature of the room temperature.

Table 1. Boundary conditions.

\begin{tabular}{|c|c|}
\hline Boundary & Variable \\
\hline \multicolumn{2}{|c|}{ Heating systems } \\
\hline $\begin{array}{c}\text { External surfaces of } \\
\text { radiators }\end{array}$ & Temperature \\
\hline $\begin{array}{c}\text { Outlets at fan coil units, } \\
\text { water fan heaters and } \\
\text { mechanical ventilation }\end{array}$ & Temperature and velocity, mass flow or gauge pressure \\
\hline $\begin{array}{c}\text { Inlets at fan coil units, } \\
\text { water fan heaters and } \\
\text { mechanical ventilation }\end{array}$ & Velocity, mass flow or vacuum pressure \\
\hline Radiant heating system & $\begin{array}{c}\text { Temperature and emissivity on the radiating surfaces; } \\
\text { emissivity of all solid surfaces, viewing the radiating surfaces }\end{array}$ \\
\hline All systems & Heat source on a subdomain covering the heated space \\
\hline \multicolumn{2}{|c|}{ Openings on the building envelopes } \\
\hline
\end{tabular}




\begin{tabular}{|c|c|}
\hline $\begin{array}{c}\text { Vertical opened } \\
\text { windows and doors } \\
\text { (opening boundaries) }\end{array}$ & $\begin{array}{r}\text { Wind pressures with positive values at the windward facades and } \\
\text { negative on the leeward ones: } p_{w}=C_{p} \rho \frac{V_{w}{ }^{2}}{2} ; \\
\text { ambient temperature } t_{a m b}\end{array}$ \\
\hline $\begin{array}{c}\text { Smoke vents on the } \\
\text { roofs (opening } \\
\text { boundaries) }\end{array}$ & $\begin{array}{c}\text { Local atmospheric pressure, computed according to the altitude. } \\
\text { ambient temperature } t_{a m b}\end{array}$ \\
\hline \multicolumn{2}{c|}{ Closed doors, windows walls, roofs and floors } \\
\hline $\begin{array}{c}\text { Heat exchanging } \\
\text { boundaries }\end{array}$ & $\begin{array}{r}\text { Coefficient of heat transfer from the internal surface to the outdoor } \\
\text { environment: } U=\frac{1}{R_{s e}+\sum_{i=1}^{n} R_{i}} ; \\
\text { ambient temperature } t_{a m b}\end{array}$ \\
\hline
\end{tabular}

The variables in the equations in Table 1 are: $p_{w}=$ wind pressure, $\mathrm{Pa} ; \rho=$ ambient air density, $\mathrm{kgm}^{-3} ; C_{p}=$ wind surface pressure coefficient, dimensionless [9]; $V_{w}=$ wind velocity, $\mathrm{ms}^{-1}$; $U=$ coefficient of thermal transmittance, $\mathrm{Wm}^{-2} \mathrm{~K}^{-1} ; R_{s e}$ and $R_{i}$ - thermal resistances of the external boundary layer and solid layers of the wall/roof/floor, $\mathrm{m}^{2} \mathrm{KW}^{-1}$.

The overall coefficient of thermal transmittance of the windows and transparent doors can be used in the last boundary condition with a sufficient accuracy for the engineering purposes.

A steady state at the chosen scenario can be achieved using pseudo-transient solution at a rational timescale and appropriate Courant number, according to the element sizes and expected velocities in the hall space [14]. The iterative solution of the model starts from an initial uniform temperature in the space, equal the design internal temperature and zero velocities of the air. The pseudo transient establishment of the airflows through the openings is obtained at that way. The computations are stopped at reaching of sufficient convergence for all variables. Another approach is modeling of the transient process of achieving the steady state after the opening of the doors or vents.

\section{Numerical simulation of the temperature and fluid flow field in a logistic storage hall}

The models above are solved numerically to estimate the temperature field and air exchange rate due to natural ventilation at a design stage of a logistic storage hall, which will be built on the territory of Sofia, Bulgaria (fig. 1). The hall is consisted of two parts, non-separated by walls and doors. The smaller part is being used for cargo input and output. There is a second level over it with office rooms. The bigger part of the hall is used for storage. There are multiple smoke vents on its roof (four of them are shown on fig. 1). A fire protecting sprinkler system is situated under the roof.

The west façade is windward as the wind direction is also west at more of the time for the region. The windows are not reflected in the geometrical model: their area ratio on the vertical walls is negligible and they are not intended to be opened.

Radiant heating is predicted to be installed in the smaller part, where the people work. One of the aims of the study is to check the possibility for water freezing in the sprinkler system without additional heating power of the bigger part of the hall.

More detail technical information about the building could not be presented due to confidential rules.

Numerical simulations of the air flow and heat transfer processes are implemented with ANSYS Workbench / CFX at working heating system and different combinations of openings and climate conditions (Table 2).

The ambient temperatures $t_{a m b}=-16^{\circ} \mathrm{C}$ and $t_{a m b}=0^{\circ} \mathrm{C}$ are the minimal and the average temperatures for the winter months in Sofia. The wind velocity $V_{w}=4 \mathrm{~ms}^{-1}$ is the maximal one for the region. 


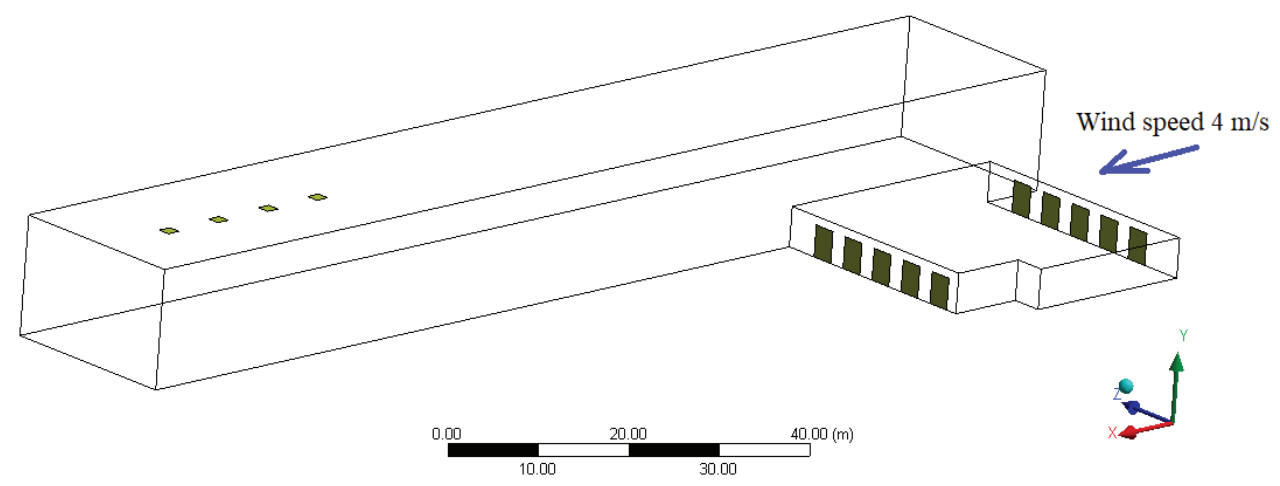

Fig. 1. Common view of the hall.

The heat transfer at the building envelopes is modeled at the conditions:

- vertical walls: $U=0.3 \mathrm{Wm}^{-2} \mathrm{~K}^{-1} ; t_{\text {amb }}$ according to Table 2 ;

- $\quad$ roof of the higher part of the hall: $U=0.3 \mathrm{Wm}^{-2} \mathrm{~K}^{-1} ; t_{a m b}$ according to Table 2;

- roof of the smaller part of the hall: $U=0.3 \mathrm{Wm}^{-2} \mathrm{~K}^{-1}$; average temperature of the second level $t=18^{\circ} \mathrm{C}$;

- floor: $U=0.5 \mathrm{Wm}^{-2} \mathrm{~K}^{-1}$; ground temperature $t=8{ }^{\circ} \mathrm{C}$;

Reference wind pressures according the atmospheric one are computed using the velocities and temperatures in Table 2 at coefficients $C_{p}=1$ for the windward facade, and $C_{p}=-$ 1 for the leeward one. The pressure on the roof vents is accepted as zero according to the atmospheric one.

The heat supply is modelled by a heat source in the subdomain of the small part of the hall. The source is computed as ratio of the thermal power of the heating installation and the volume of the subdomain. $k-\varepsilon$ turbulence model is used to model the airflows. The buoyancy is modelled, taking into account the gravity and a reference density, equal to the density of the ambient air at the correspondent temperature.

The heat transfer with the cargo is not taken into account, as the intensity and the mass of the supplied materials are not known at the design stage.

Table 2. Modelled scenarios and results about the air exchange.

\begin{tabular}{|c|l|c|c|c|c|}
\hline № & Conditions for numerical simulation & $\begin{array}{c}\text { Mass } \\
\text { airflow } \\
\mathrm{kgh}^{-1}\end{array}$ & $\begin{array}{c}\text { Average internal } \\
\text { temperature } \\
{ }^{\circ} \mathrm{C}\end{array}$ & $\begin{array}{c}\text { Volume } \\
\text { airflow } \\
\mathrm{m}^{3} \mathrm{~h}^{-1}\end{array}$ & $\begin{array}{c}\mathrm{ARCH} \\
\mathrm{h}^{-1}\end{array}$ \\
\hline 1 & $\begin{array}{l}\text { Closed roof vents, } 2 \text { opened opposite } \\
\text { doors, } t_{a m b}=-16^{\circ} \mathrm{C}, V_{w}=4 \mathrm{~ms}^{-1}\end{array}$ & 140040 & 1 & 108703 & 2.28 \\
\hline 2 & $\begin{array}{l}4 \text { opened roof vents, } 2 \text { opened opposite } \\
\text { doors, } t_{a m b}=-16^{\circ} \mathrm{C}, V_{w}=4 \mathrm{~ms}^{-1}\end{array}$ & 173232 & -4 & 132014 & 2.77 \\
\hline 3 & $\begin{array}{l}4 \text { opened roof vents, } 10 \text { opened doors, }^{-1} \\
t_{\text {amb }}=-16^{\circ} \mathrm{C}, V_{\text {wind }}=4 \mathrm{~ms}^{-1}\end{array}$ & 844524 & -5 & 641188 & 13.48 \\
\hline 4 & $\begin{array}{l}4 \text { opened roof vents, } 2 \text { opened opposite }^{-1} \\
\text { doors, } t_{a m b}=0^{\circ} \mathrm{C}, V_{w}=4 \mathrm{~ms}^{-1}\end{array}$ & 153864 & 8 & 122485 & 2.57 \\
\hline
\end{tabular}

The models are verified by mass and energy balances, done on the base of the obtained results. The differences between the mass flows, entering and leaving the rooms, are less than $1 \%$. The differences between the input heat flow and sum output heat flows are below $5 \%$. So the obtained results can be accepted as reliable in order to estimate the processes at the modelled variants. 
The computed temperature, pressure and velocity fields are obvious can be seen on the figures below. The pressure distribution caused by the buoyancy force in the bigger part of the hall is shown in figure 5. The pressure stratification is decreased at opened roof vents because of the air leakage due to the stack effect.

The flows, entering and leaving the hall, the average internal temperature and the air exchange rate per hour (ARCH) are given in Table 2. According to [9], the volumetric airflow due to stack and wind effects at building with high infiltration air, is computed using ARCH in the limits of 4 and $10 \mathrm{~h}^{-1}$ at pressure difference of $50 \mathrm{~Pa}$ between the internal and external pressure. The $\mathrm{ARCH}$, obtained at the simulations are results of smaller pressure differences, however they are in the limits above, excepting the case at all opened doors.

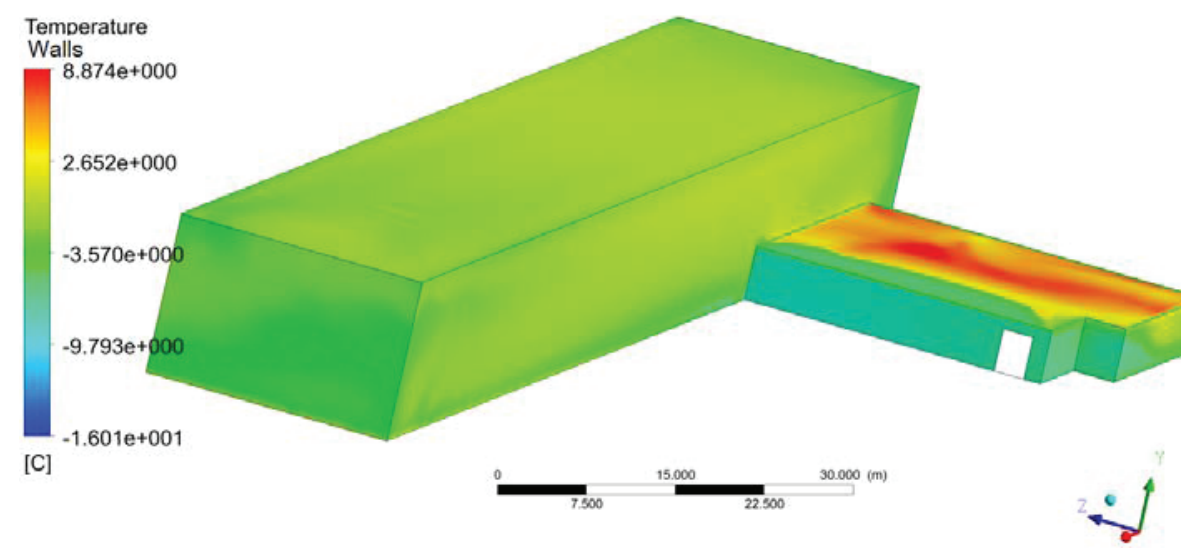

Fig. 2. Temperature field of the internal surfaces of the walls at scenario 1 .
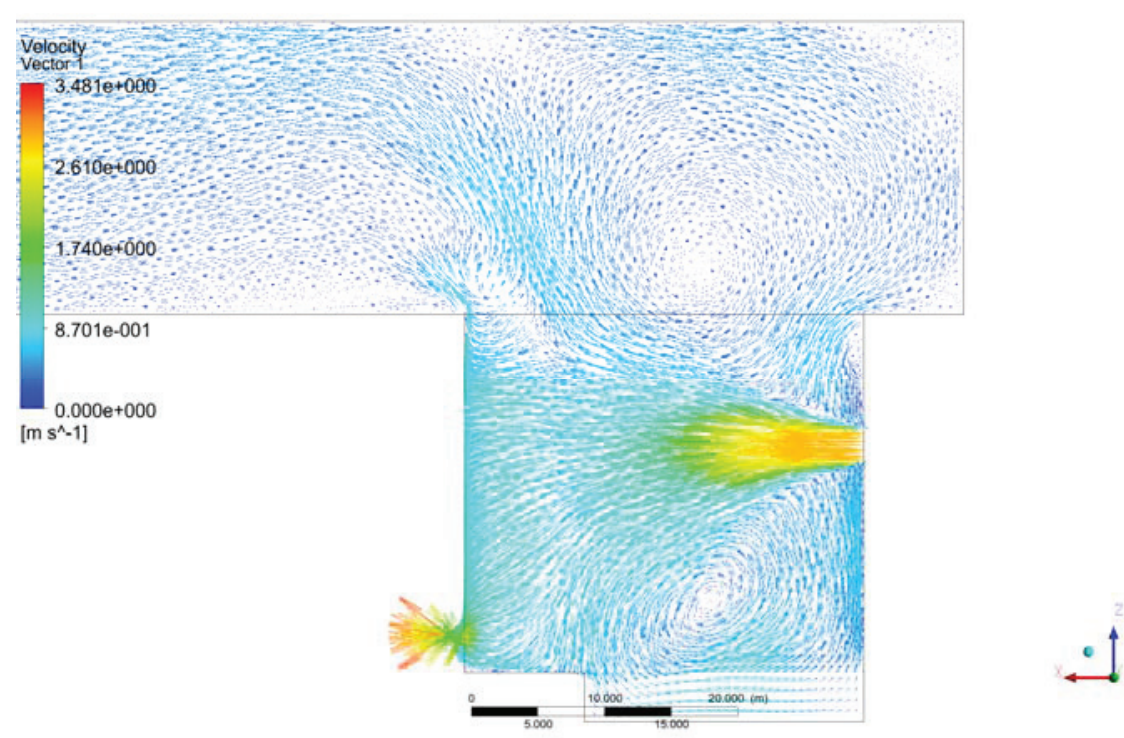

Fig. 3. Velocity field in a horizontal cross section at scenario 1. 


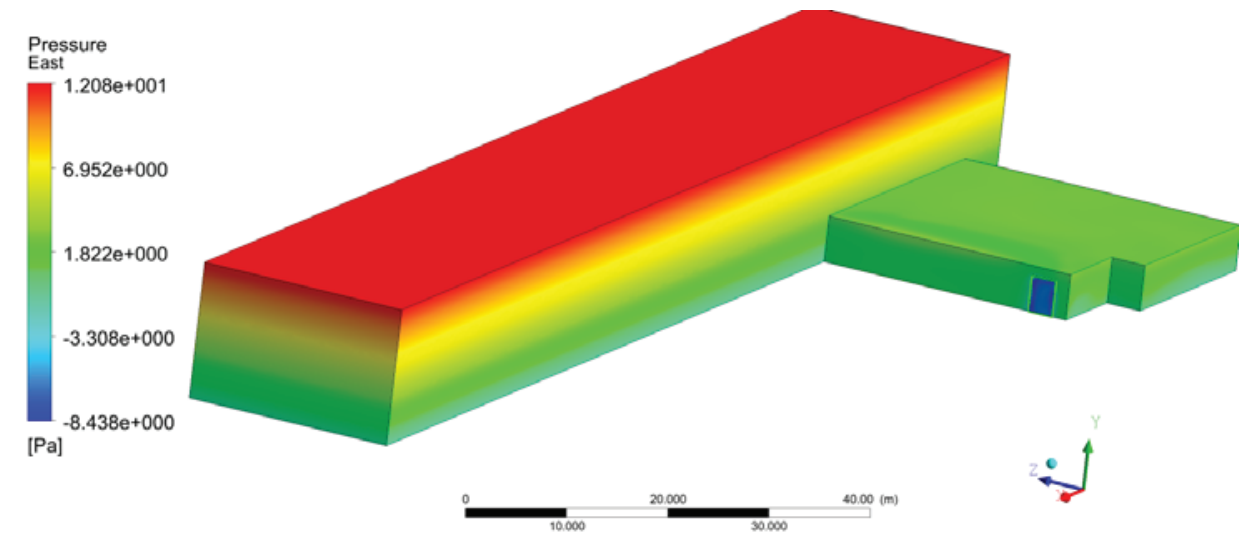

Fig. 4. Pressure field at scenario 1.

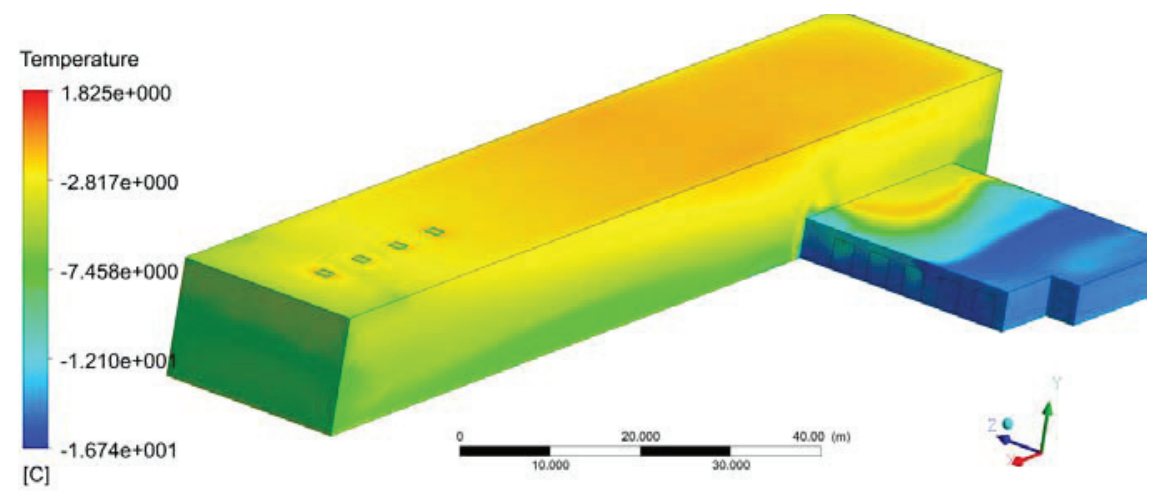

Fig. 5. Temperature field of the internal surfaces of the walls at scenario 3 .

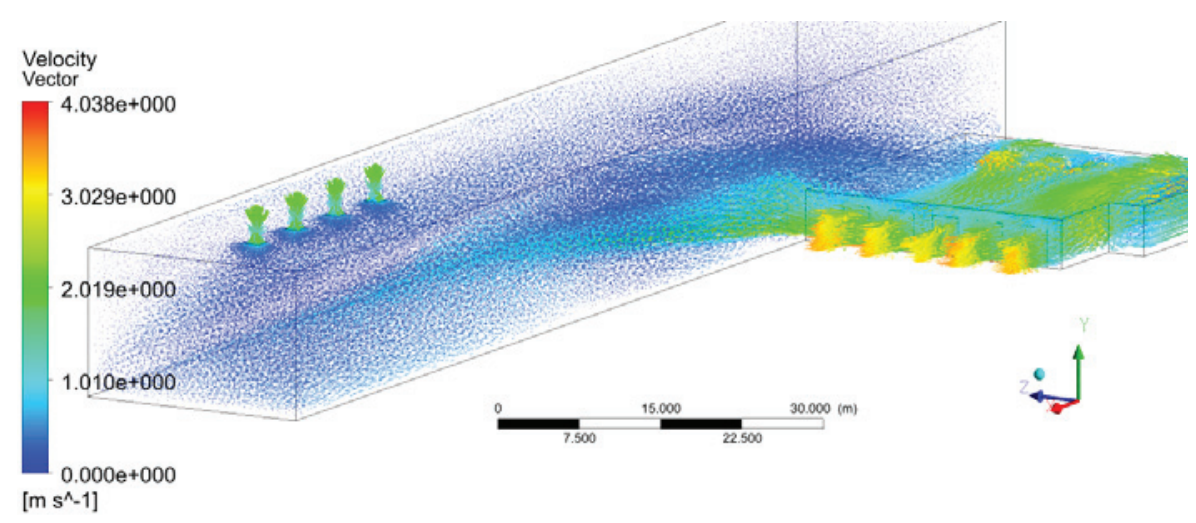

Fig. 6. Velocity fields in a horizontal cross section at scenario 3. 


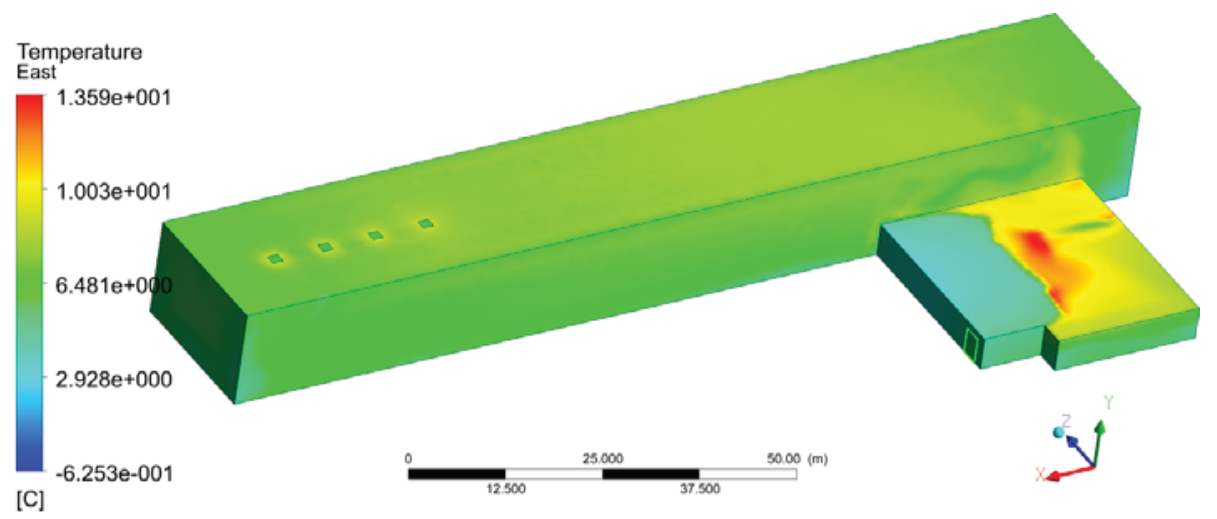

Fig. 7. Temperature field of the internal surfaces of the walls at scenario 4.

\section{Discussion and recommendations}

$\checkmark$ The temperature of the inner surface of the roof of the large hall at an external temperature of $-16{ }^{\circ} \mathrm{C}$, closed roof vents and two opposite continuously open doors varies in the range from $-3{ }^{\circ} \mathrm{C}$ to $-1{ }^{\circ} \mathrm{C}$ (fig. 2). It is further reduced to $-5{ }^{\circ} \mathrm{C}$ at all opened doors and vents, visible in fig. 5 . Therefore, additional heating capacity has to be provided in this part of the hall to prevent the risk of water freezing in the sprinkler system.

$\checkmark$ The average temperature in the small hall is below $-5{ }^{\circ} \mathrm{C}$ due to the large flow of cold air at opened 10 doors at the same time (5 on the opposite facades) and an outdoor temperature of $-16{ }^{\circ} \mathrm{C}$. The average temperature in the large hall will also be negative. Therefore, this situation should not be allowed in cases of negative outside temperatures and wind.

$\checkmark$ At an outdoor temperature of $0{ }^{\circ} \mathrm{C}$, the installed heating capacity of the small hall will be sufficient to maintain positive temperatures $\left(6-7^{\circ} \mathrm{C}\right)$ on the inner surface of the roof of the high part. Therefore, the auxiliary heating in the large hall can be stopped at temperatures above $0{ }^{\circ} \mathrm{C}$ without a risk of freezing of the sprinkler systems.

\section{Conclusions}

The proposed concepts for modeling and numerical simulations allow analyses of the natural ventilation and heat transfer in logistic storage halls at variations of climatic conditions, openings and heating capacities. The further development of the models, taking into account of the intensity, mass and temperatures of supplied and leaving loads will enable obtaining of information about the heat exchange in the halls under real operation conditions.

The investigations in that paper have been implemented with the financial support of National Programme "Young scientist and postdoctoral students", funded by Bulgarian Ministry of Education.

The numerical simulations are done in Center of mathematical modeling and computer simulation at University of Chemical Technology and Metallurgy. 


\section{References}

1. M. Bartak, I. Beausoleil-Morrison, J. Clarke, J. Denev, F. Drkal, M. Lain, I. Macdonald, A. Melikov, Z. Popiolek, and P. Stankov, Building and Environment 37, 89, 865-871 (2002)

2. D. Piscia, Pere Muñoz, C. Panadès, and J. I. Montero, Computers and Electronics in Agriculture 115, 129-141 (2015)

3. T. V. Hung, N. Kaloyanov, M. Vassilev, Proceedings of the XXI Scientific Conference with International Participation FPEPM 2016 (in Bulgarian), 1, 286-293 (2016)

4. R. Kim, S. Hong, T. Norton, T. Amon, A. Youssef, D. Berckmans and I. Lee, Biosystems Engineering, 193, 232-246 (2020)

5. P. Zlateva P, K. Yordanov K, IOP Conference Series: Materials Science and Engineering, 595, 1, 012017 (2019)

6. G. Pichurov, P Stankov and D. Markov, IFAC Proceedings Volumes, 39 (19), 213-218 (2006)

7. B Stankov, N. Kaloyanov and G. Tomov, Towards Energy Sustainability, 25-37 (2017)

8. Bulgarian regulation № $4 / 21.05 .2001$ on the scope and content of the investment projects (2004)

9. American Society of Heating, Refrigerating and Air-Conditioning Engineers (ASHRAE), Chapter 16 : Ventilation and infiltration (2007)

10. Bulgarian regulation № 15 of 28 July 2005 on technical rules and standards for design, construction and operation of sites and facilities for heat generation, transmission and distribution (2016)

11. D. Etheridge, and B. Ford, CTBUH $8^{\text {th }}$ world congress, 3-5 (2008)

12. J. Cheung and C. Liu, Energy and Buildings, 43 (5), 1149-1158 (2011)

13. N. Hur, M. Lee and S. Yang, Korean Journal of Air-Conditioning and Refrigeration Engineering, 19 (5), 379-385 (2007)

14. ANSYS Release 16 - (C) SAS IP, Inc. (2016) 